\title{
Smoldering Systemic Mastocytosis
}

National Cancer Institute

\section{Source}

National Cancer Institute. Smoldering Systemic Mastocytosis. NCI Thesaurus. Code

C115460.

Slowly progressive systemic mastocytosis with uncertain prognosis. It is characterized by organomegaly and absence of aggressive disease. 